\title{
Analysis of the Axial Filaments of Treponema hyodysenteriae by SDS-PAGE and Immunoblotting
}

\author{
By K. A. KENT, ${ }^{*} \dagger$ R. SELLWOOD, R. M. LEMCKE, M. R. BURROWS \\ AND R. J. LYSONS \\ AFRC, Institute for Animal Health, Compton Laboratory, Compton, Newbury, \\ Berks RG16 ONN, UK
}

(Received 30 September 1988; accepted 9 February 1989)

\begin{abstract}
Purified axial filaments from eight serotypes of Treponema hyodysenteriae and two nonpathogenic intestinal spirochaetes were characterized by SDS-PAGE and Western blotting. Axial filaments of all ten strains had similar SDS-PAGE profiles; five major axial filament polypeptides were identified, with molecular masses of $43.8,38,34 \cdot 8,32 \cdot 8$ and $29.4 \mathrm{kDa}$. Hyperimmune gnotobiotic pig serum raised against purified axial filaments of strain P18A (serotype 4) cross-reacted with all other serotypes and with the non-pathogens, and convalescent serum taken from a pig with persistent swine dysentery also showed a strong response to the axial filament polypeptides. Hyperimmune gnotobiotic pig serum raised against axial filaments failed to agglutinate viable organisms and did not inhibit growth in vitro. Hence, the axial filaments of $T$. hyodysenteriae have been identified as major immunodominant antigens, although the role that antibodies to these antigens play in protection has yet to be established.
\end{abstract}

\section{INTRODUCTION}

Swine dysentery is a severe mucohaemorrhagic diarrhoea which affects the colon of the growing pig (Harris \& Glock, 1986). Treponema hyodysenteriae has been identified as the causative agent (Taylor \& Alexander, 1971; Harris et al., 1972) and, together with other bacterial species such as Fusobacterium and Bacteroides spp., gives rise to the severe clinical disease seen in conventional pigs (Harris et al., 1978; Lysons et al., 1978; Joens et al., 1981). Only a mild form of the disease is seen when gnotobiotic pigs are infected with $T$. hyodysenteriae alone (Whipp et al., 1982).

Humoral (Joens et al., 1979; Egan et al., 1983; Burrows et al., 1984) and mucosal (Joens et al., 1984) immune responses to infection have been observed although little is known of the immune response to specific antigens of $T$. hyodysenteriae. Joens \& Marquez (1986) compared antigens of a virulent strain of $T$. hyodysenteriae with those of a non-pathogenic intestinal spirochaete. They showed that an immune response to numerous antigens could be detected by immunoblotting with sera taken from pigs during clinical disease and convalescence although the cellular location of these antigens was not established. A single antigen unique to $T$. hyodysenteriae was also observed. Chatfield et al. (1988) observed antigens unique to a virulent strain of $T$. hyodysenteriae which were thought to be outer envelope polypeptides when hyperimmune rabbit sera and post-vaccination porcine sera were used in immunoblotting experiments.

In studies of Leptospira spp. (Chapman et al., 1988), Borrelia spp. (Craft et al., 1986; Barbour et al., 1983) and Treponema spp. (Hanff et al., 1982; Baker-Zander et al., 1985) antibodies to axial filament polyeptides have been demonstrated in patients with disease. Moreover,

† Present address: National Institute for Biological Standards and Control, Blanche Lane, South Mimms, Potters Bar, Hertfordshire EN6 3QG, UK. 
treponemicidal activity of normal human serum against Treponema pallidum has been correlated with immunoglobulin $\mathrm{G}$ directed against endoflagellar polypeptides (Blanco et al., 1986). Therefore, antibodies to the axial filaments of $T$. hyodysenteriae may play an important role in protection of pigs from swine dysentery.

This investigation was concerned with the characterization of the axial filaments of ten different spirochaetes. Eight strains of $T$. hyodysenteriae representative of all known lipopolysaccharide (LPS) serotypes and two strains of a non-pathogenic, intestinal spirochaete were examined by SDS-PAGE and immunoblotting using convalescent and polyclonal hyperimmune porcine sera.

\section{METHODS}

Bacterial strains. Eight strains of Treponema hyodysenteriae were used throughout this investigation, together with two porcine isolates that could not be identified as $T$. hyodysenteriae and were not pathogenic for pigs (Table 1). B78, S75/1, B169, P18A, KF9, VS1 and MC52/80 were used as representative of the seven LPS serotypes of $T$. hyodysenteriae identified by Lemcke \& Bew (1984). P35/2 was a new field isolate which is serologically distinct from other serotypes of $T$. hyodysenteriae and hence represents a new serotype (unpublished observation). The non-pathogens PWS/A and M1 were isolated from healthy pigs (Hudson et al., 1976; Lemcke \& Burrows, 1979).

All strains were cultivated in trypticase soya broth supplemented with $5 \%(\mathrm{v} / \mathrm{v})$ rabbit serum as described by Kent et al. (1988).

Preparation and purification of axial filaments. Axial filaments were prepared from all strains by a modification of the method described by Hardy et al. (1975). One-litre cultures were harvested by centrifugation at $15000 \mathrm{~g}$ for $30 \mathrm{~min}$ at $4{ }^{\circ} \mathrm{C}$ and washed once with phosphate-buffered saline $\left(0.17 \mathrm{M}-\mathrm{NaCl}, 3.35 \mathrm{mM}-\mathrm{KCl}, 0.01 \mathrm{M}-\mathrm{Na}_{2} \mathrm{HPO}_{4}\right.$, $1.84 \mathrm{mM}-\mathrm{KH}_{2} \mathrm{PO}_{4}$, pH 7.2) containing $0.01 \mathrm{M}-\mathrm{MgCl}_{2}$ and $0.01 \mathrm{M}-\mathrm{CaCl}_{2}$ (complete PBS) and pellets were suspended in the same buffer. Outer envelopes were removed by the addition of SDS to a final concentration of $0.01 \%$. The suspension was incubated for $15 \mathrm{~min}$ at room temperature with occasional agitation and the organisms then collected by centrifugation at $25000 \mathrm{~g}$ for $30 \mathrm{~min}$ at $4{ }^{\circ} \mathrm{C}$. The pellets were resuspended in $10 \mathrm{ml}$ complete PBS and blended for 2 min using a Universal blender (MSE). Filaments were recovered in the supernatant by pelleting the remaining organisms at $30000 \mathrm{~g}$ for $30 \mathrm{~min}$ at $4{ }^{\circ} \mathrm{C}$. The blending was repeated up to 10 times for each strain, and filaments from each step were checked by electron microscopy for contaminating structures, e.g. membranes. The filament preparations were pooled and sodium lauroyl sarkosinate (Sarkosyl) was added to $0 \cdot 2 \%(\mathrm{w} / \mathrm{v})$ final concentration. Filaments were sedimented by centrifugation at $94000 \mathrm{~g}$ for $60 \mathrm{~min}$ at $4{ }^{\circ} \mathrm{C}$ and were purified by isopycnic gradient centrifugation in caesium chloride $(0.359 \mathrm{~g} \mathrm{CsCl}+1 \mathrm{ml}$ double-distilled water, $\rho=1.25)$ at $100000 \mathrm{~g}$ for $48-65 \mathrm{~h}$ at $10^{\circ} \mathrm{C}$. A band at approximately $1.3 \rho$ was collected in double-distilled water and then centrifuged at $94000 \mathrm{~g}$ for $60 \mathrm{~min}$ at $4{ }^{\circ} \mathrm{C}$. Purified filaments were resuspended in double-distilled water, checked by electron microscopy and SDS-PAGE and stored at $-20^{\circ} \mathrm{C}$.

SDS-PAGE and Western blotting. SDS-PAGE was carried out using the discontinuous buffer system of Laemmli (1970). Vertical slab gels were prepared with a $12 \%(\mathrm{w} / \mathrm{v})$ acrylamide running gel and $3 \cdot 75 \%$ stacking gel. Samples were dissociated by boiling in $62.5 \mathrm{~mm}$-Tris/ $\mathrm{HCl} \mathrm{pH} 6.8,2 \%(\mathrm{w} / \mathrm{v}) \mathrm{SDS}, 2 \%(\mathrm{v} / \mathrm{v}) 2$-mercaptoethanol and $1 \%(\mathrm{v} / \mathrm{v})$ glycerol. Low-molecular-mass markers were obtained from Pharmacia. Gels were run at a constant voltage of $150 \mathrm{~V}$ for 3-5 h and were either stained with PAGE Blue 83 (BDH) or Western blots were performed using the method described by Towbin et al. (1979). Polypeptides were transferred to nitrocellulose (Schleicher \& Schuell) overnight at $35 \mathrm{~V}$. After transfer, the nitrocellulose was blocked with $20 \%(\mathrm{v} / \mathrm{v})$ foetal calf serum (FCS) in 0.05 M-Tris-buffered saline, $\mathrm{pH} 8.0$ (TBS) for $1 \mathrm{~h}$ on a rocking platform. The nitrocellulose was then incubated with dilutions of antisera $(1 / 100)$ in TBS containing $20 \% \mathrm{FCS}$ for $1 \mathrm{~h}$. After incubation, the antiserum was removed and the nitrocellulose washed for 15 min each with TBS, TBS + Nonidet-P40 $(0 \cdot 1 \%, v / v)$ and TBS before addition of $0.1 \mu \mathrm{Ci}(37 \mathrm{kBq})^{125} \mathrm{I}$-Protein A per ml TBS (containing $20 \% \mathrm{FCS}$ ) for $1 \mathrm{~h}$. The washing steps were repeated and the nitrocellulose allowed to dry. Autoradiographs using RX-type X-ray film (Fuji) were exposed with enhancing screens for $4-24 \mathrm{~h}$ at $-70^{\circ} \mathrm{C}$.

Preparation of antisera. Antiserum to purified axial filaments of $T$. hyodysenteriae strain P18A was raised in a 14-d-old gnotobiotic pig. Protein ( $1.5 \mathrm{mg}$ ) was emulsified in Freund's incomplete adjuvant (Gibco) in a total volume of $2 \mathrm{ml}$ and administered subcutaneously. The immunization was repeated after 2 weeks at a second subcutaneous site. The animal was test bled $14 \mathrm{~d}$ later and the serum collected at exsanguination was designated $\mathrm{C} 11$.

Rabbit antisera against intact bacteria were raised by subcutaneous and intravenous inoculation as described by Lemcke \& Burrows (1979).

Convalescent serum (CPS) was obtained from a conventionally reared pig. The animal was infected at 6 weeks of age and had persistent swine dysentery for several weeks. Serum was collected at post-mortem 12 weeks postinfection. 
Table 1. Strains used

\begin{tabular}{llll} 
Strain & Origin & Serotype & \multicolumn{1}{c}{ Reference } \\
B78 & USA & 1 & Baum \& Joens (1979) \\
S75/1 & GB & 2 & Baum \& Joens (1979); Lemcke \& Bew (1984) \\
B169 & Canada & 3 & Baum \& Joens (1979) \\
P18A & GB & 4 & Baum \& Joens (1979); Lemcke \& Bew (1984) \\
KF9 & GB & 5 & Lemcke \& Bew (1984) \\
VS1 & GB & 6 & Lemcke \& Bew (1984); Lysons et al. (1982) \\
MC52/80 & GB & 7 & Lemcke \& Bew (1984) \\
P35/2 & GB & New & (K. A. Kent, unpublished observation) \\
PWS/A & GB & Non-pathogen & Hudson et al. (1976) \\
M1 & GB & Non-pathogen & Lemcke \& Burrows (1979)
\end{tabular}

Slide agglutination test. This was done according to the method described by Burrows \& Lemcke (1981).

Growth inhibition test. The ability of sera to inhibit growth of $T$. hyodysenteriae was determined by the method of Lemcke \& Burrows (1979). Briefly, suspensions of broth-grown $T$. hyodysenteriae strains were inoculated onto rabbit serum agar and excess inoculum was removed. Plates were allowed to dry and then antibiotic assay discs ( $6 \mathrm{~mm}$ diameter) impregnated with undiluted hyperimmune rabbit serum were applied. Plates were incubated under anaerobic conditions at ambient temperature for $18 \mathrm{~h}$ followed by $3-5 \mathrm{~d}$ at $37^{\circ} \mathrm{C}$. After incubation, the sizes of the zones of growth inhibition were measured from the outer edge of the disc to the edge of the inhibition zone.

Electron microscopy. The axial filament preparations and suspensions of spirochaetes were negatively stained with $2 \%(\mathrm{w} / \mathrm{v})$ ammonium molybdate on Formvar coated copper grids. Immunogold labelling was performed as follows. Axial filaments or spirochaete suspensions were placed on Formvar-coated nickel grids and allowed to dry. The grids were treated with hyperimmune porcine serum $(\mathrm{C} 11)$ for $30 \mathrm{~min}$. After rinsing in distilled water the grids were treated with $10 \mathrm{~nm}$ Protein A-gold particles (Janssen) for $15 \mathrm{~min}$. After further rinsing the suspensions were negatively stained with ammonium molybdate and viewed in a Philips EM300 electron microscope.

\section{RESULTS}

\section{Purification and SDS-PAGE analysis of axial filaments}

An electron micrograph of a $\mathrm{CsCl}$-purified preparation of axial filaments from T. hyodysenteriae strain P18A is shown in Fig. 1. Two distinct bands were sometimes observed after gradient centrifugation but both bands appeared similar by electron microscopy and SDSPAGE. Preparations from all the strains investigated were of similar appearance. Filaments that possessed a hook were occasionally observed and the filaments generally had a striated appearance. 'Thick' and 'thin' filaments were frequently observed. SDS-PAGE analysis of axial filaments from eight strains of $T$. hyodysenteriae and two non-pathogenic strains revealed the presence of several major polypeptides (Fig. 2), which ranged in size from approximately $29 \mathrm{kDa}$ to $46 \mathrm{kDa}$. The axial filaments of $T$. hyodysenteriae strain P18A (lane 4), the representative serotype of British isolates, gave five major polypeptide bands: AF1 $43.8 \mathrm{kDa}$; AF2, 38.0 kDa; AF3, 34.8 kDa; AF4, 32.8 kDa; and AF5, 29.4 kDa. Two of these bands (AF1 and AF3) appeared to contain more than one component. Filaments of other strains gave bands of similar size but with one or two obvious differences. The $43.8 \mathrm{kDa}$ (AF1) polypeptide of all other strains of $T$. hyodysenteriae did not resolve clearly as a doublet. AF1 of strains P35/2 (lane 8) and PWS/A (lane 9) had a lower molecular mass (42.0 kDa) than that of other strains, whereas the non-pathogen M1 (lane 10) had a higher molecular mass of $46.0 \mathrm{kDa}$. AF2 of all strains appeared similar. The $34.8 \mathrm{kDa}$ polypeptide (AF3) appeared in all $T$. hyodysenteriae strains as a triplet, except in strains B78 (lane 1) and MC52/80 (lane 7), where it was a doublet. In the two non-pathogenic spirochaetes (lanes 9 and 10) this was a single band. AF4 and AF5 were similar in all strains, with AF4 resolving as a single band and AF5 resolving as a doublet.

\section{Immunogold labelling}

Fig. 3 shows the protein A-gold labelling of T. hyodysenteriae strain P18A labelled with hyperimmune gnotobiotic pig serum $(\mathrm{C} 11)$ raised against purified axial filaments. The gold particles labelled the surface of the filaments that had been released from the organism during 


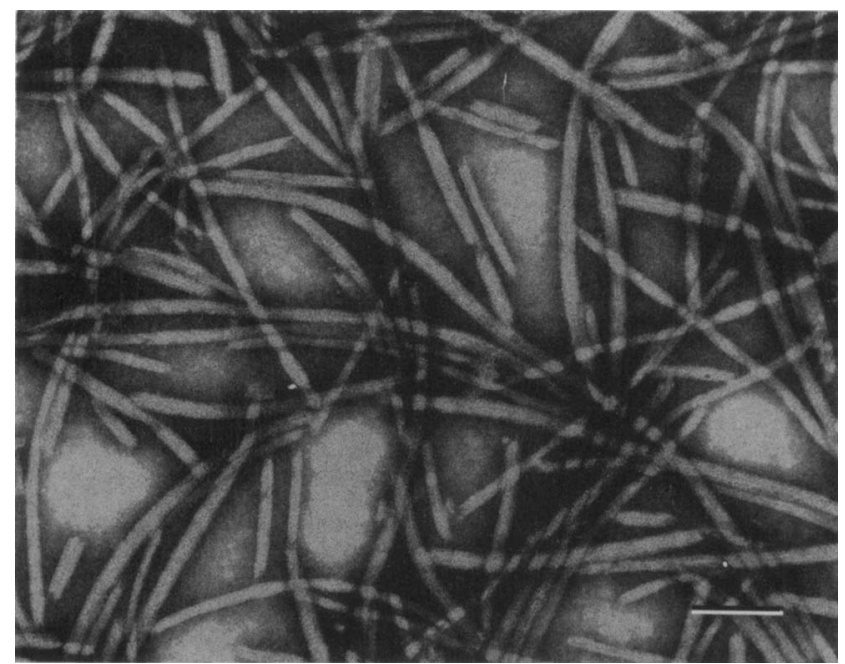

Fig. 1. Electron micrograph of caesium chloride purified axial filaments of $T$. hyodysenteriae strain P18A negatively stained with ammonium molybdate. Bar, $0 \cdot 1 \mu \mathrm{m}$.

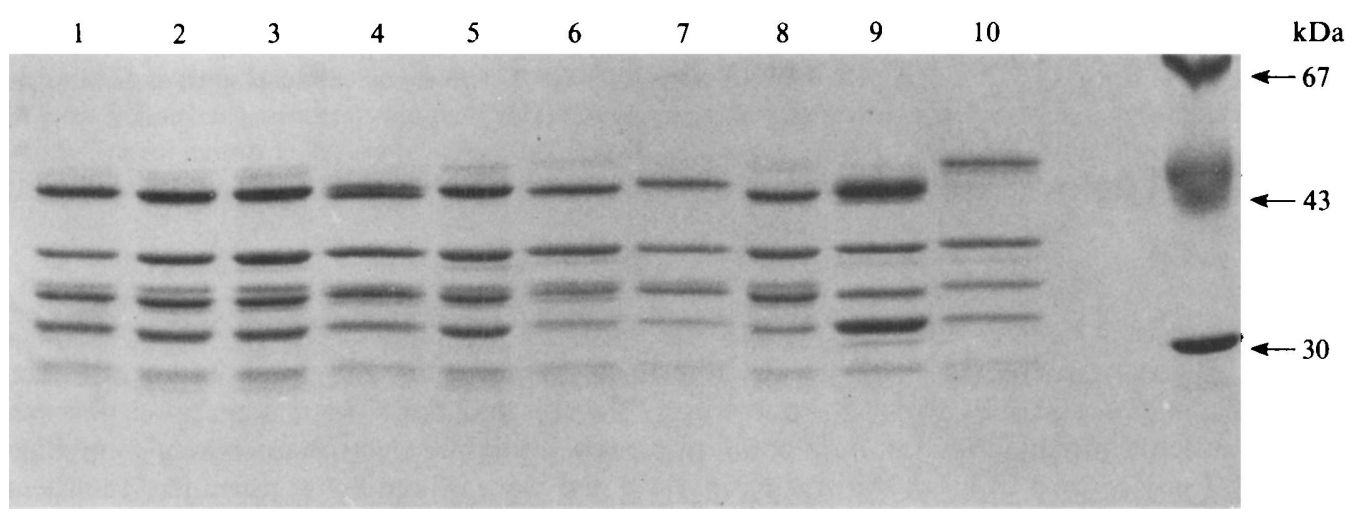

Fig. 2. Axial filament polypeptides of eight strains of $T$. hyodysenteriae and two non-pathogenic intestinal spirochaetes separated by SDS-PAGE and stained with PAGE Blue 83. Lane 1, B78; lane 2, S75/1; lane 3, B169; lane 4, P18A; lane 5, KF9; lane 6, VS1; lane 7, MC52/80; lane 8, P 35/2; lane 9 , PWS/A; lane 10, M1. Molecular mass markers are indicated by arrows.

preparation of the sample on the copper grid. Gold particles were not observed attached to the outer envelope of the spirochaete.

\section{Slide agglutination and growth inhibition tests}

There was no agglutination of any strain of T. hyodysenteriae or of the non-pathogenic spirochaetes by $\mathrm{C} 11$ serum, whereas hyperimmune rabbit serum raised against whole P18A agglutinated all eight strains of $T$. hyodysenteriae but not the non-pathogenic spirochaetes M1 and PWS-A.

In the growth inhibition test, $\mathrm{C} 11$ serum gave no zones of inhibition with any of the strains of spirochaete tested. The hyperimmune rabbit serum raised against whole P18A gave $4-8 \mathrm{~mm}$ zones of inhibition of growth with all strains of $T$. hyodysenteriae but no inhibition with the nonpathogenic spirochaetes.

\section{Western blotting}

In Western blot analysis, convalescent porcine serum (CPS) reacted with the five polypeptides of the axial filaments of all ten strains, including the non-pathogens (Fig. $4 a$ ). 


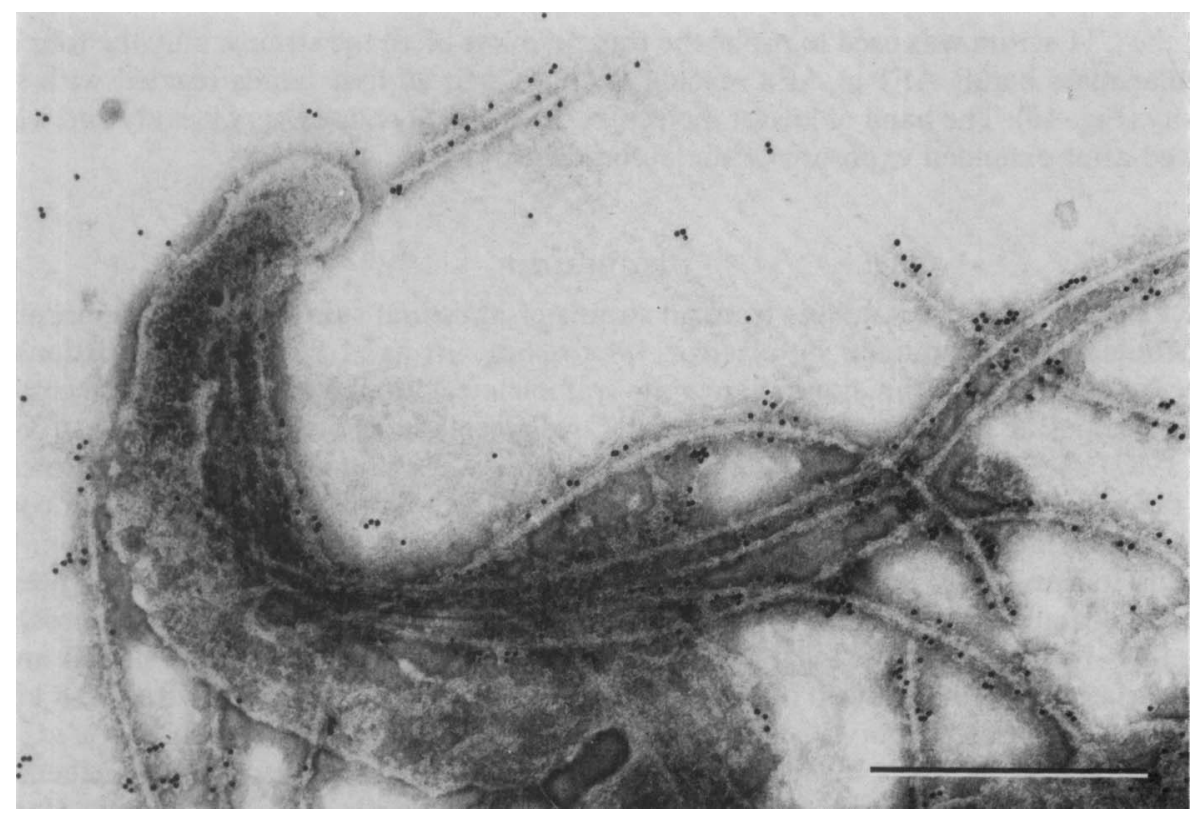

Fig. 3. Immunogold labelling of whole organisms of $T$. hyodysenteriae strain P18A using hyperimmune gnotobiotic pig serum $(\mathrm{C} 11)$. Bar, $0 \cdot 5 \mu \mathrm{m}$.

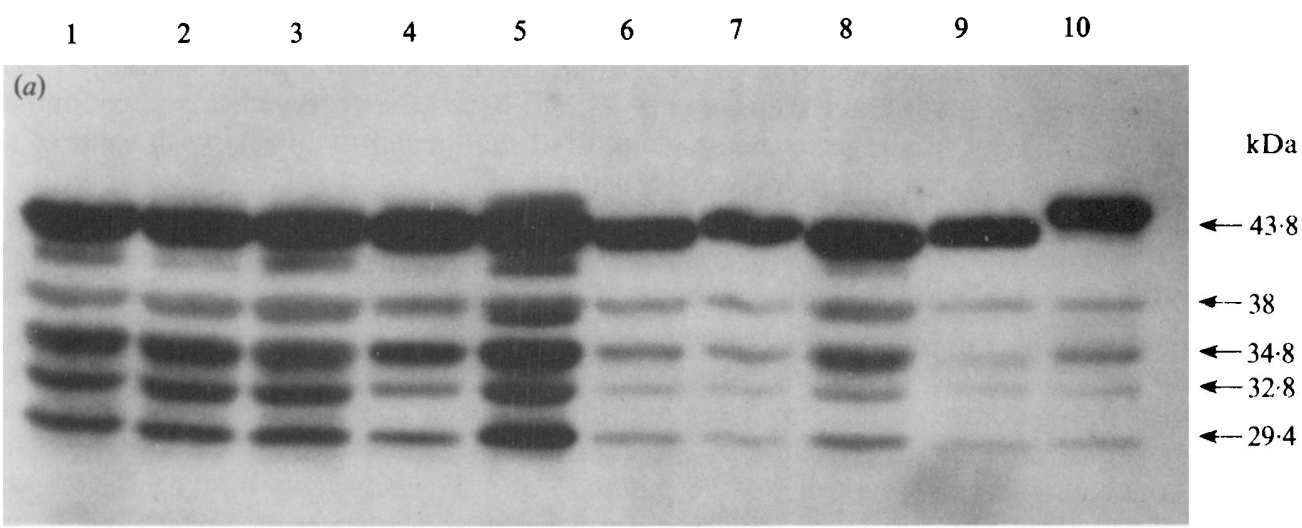

(b)

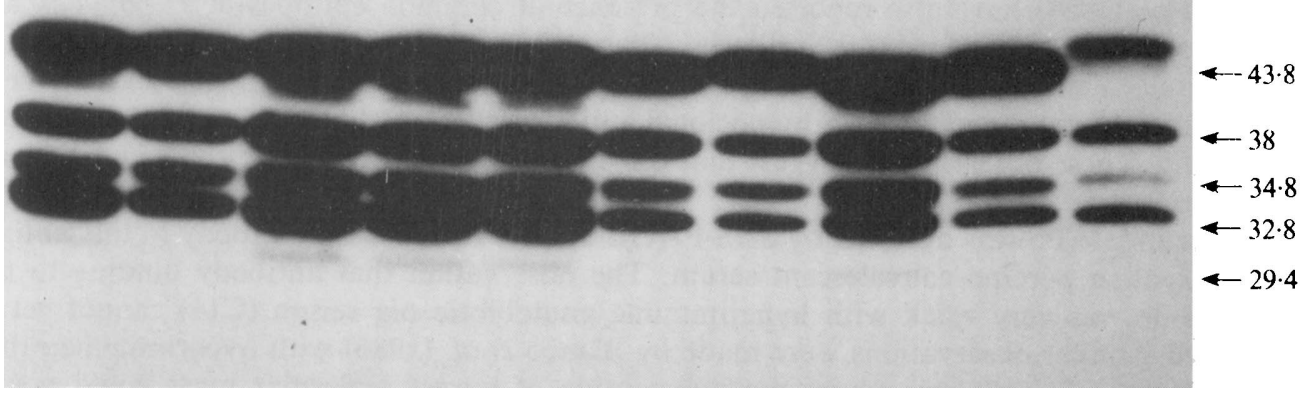

Fig. 4. Western blots of the axial filament polypeptides from eight strains of $T$. hyodysenteriae and two non-pathogenic intestinal spirochaetes. Polypeptides were separated on a $12 \%$ acrylamide SDS-PAGE gel, blotted onto nitrocellulose and probed with $(a)$ convalescent porcine serum (CPS) and $(b)$ hyperimmune gnotobiotic pig serum (C11). Lane 1, B78; lane 2, S75/1; lane 3, B169; lane 4, P18A; lane 5, KF9; lane 6, VS1; lane 7, MC52/80; lane 8, P35/2; lane 9, PWS/A; lane 10. M1. Molecular masses of the major polypeptides are shown. 
When the C11 serum was used to probe the transfer blots of all the strains, only the four higher molecular mass bands AF1 to AF4 reacted strongly, and all four bands reacted with similar intensity (Fig. $4 b$ ). The band of lowest molecular mass (AF5) reacted very weakly and was only observed after extended exposure of the autoradiograph.

\section{DISCUSSION}

The axial filament preparations from all strains of intestinal spirochaetes were morphologically similar when examined by electron microscopy. In axial filament preparations from $T$. hyodysenteriae and the non-pathogenic spirochaetes 'thick' and 'thin' filaments were observed, a finding similar to that reported for T. pallidum (Sand-Petersen et al., 1981; Cockayne et al., 1987) and Leptospira spp. (Nauman et al., 1969; Kelson et al., 1988), where 'thick' and 'thin' filaments are known to be sheathed and unsheathed filaments respectively. In contrast, the axial filaments of Borrelia spp. are reported to be of uniform thickness along their length (Hovind-Hougen, 1974; Barbour \& Hayes, 1986). The hook structure reported to be present in most spirochaetes was occasionally observed in preparations from the intestinal spirochaetes.

The SDS-PAGE profiles of axial filaments of all strains examined were also similar and only minor variations were observed. The five polypeptides of $43 \cdot 8,38,34 \cdot 8,32 \cdot 8$ and $29 \cdot 4 \mathrm{kDa}$ are similar to those described for T. pallidum and T. phagedenis biotype Reiter (Blanco et al., 1986), in which five polypeptides of 35,33 (doublet), 30 and $27 \mathrm{kDa}$ have been described. Axial filaments from Leptospira spp. have six polypeptides (Nauman et al., 1969) whereas Hansen $e t$ al. (1988) report the presence of only one polypeptide in Borrelia burgdorferi axial filaments. Occasionally when axial filaments were purified on $\mathrm{CsCl}$ two bands were observed close together. Both bands contained morphologically identical axial filaments which had the same SDS-PAGE profile, In the purification of $T$. phagedenis, $T$. pallidum and $B$. burgdorferi axial filaments, Blanco et al. (1986) and Hansen et al. (1988) have also observed this phenomenon. These bands may have arisen due to the association of non-protein material with some of the axial filaments, thus affecting their buoyant density.

The cross-reaction of the hyperimmune gnotobiotic porcine serum $(\mathrm{C} 11)$ and the convalescent serum (CPS) with the axial filament bands of all the strains of intestinal spirochaetes demonstrates the presence of shared epitopes. In a study of $T$. hyodysenteriae and nonpathogenic intestinal spirochaetes ( $T$. innocens), Joens \& Marquez (1986) demonstrated that sera taken from pigs with acute clinical swine dysentery cross-reacted with polypeptides from both species. Numerous common antigens were identified as well as some that were specific for $T$. hyodysenteriae. However, the nature of these antigens was not determined. Cross-reaction between axial filament polypeptides of $T$. pallidum and $T$. phagedenis biotype Reiter with hyperimmune rabbit (Blanco et al., 1988), normal human (Blanco et al., 1986) and human syphilitic sera (Hardy et al., 1975) has been reported. Baker-Zander \& Lukehart (1984) and Bailey et al. (1987) have also reported the presence of common epitopes of $T$. pallidum and $T$. hyodysenteriae axial filaments. Similarly, Chapman et al. (1988) observed cross-reaction of axial filaments among the Leptospira spp. using hyperimmune rabbit serum, and Barbour et al. (1986) reported cross-reaction of a monoclonal antibody with axial filaments of several species of Borrelia. These observations suggest that the axial filament polypeptides of each genus are highly conserved.

Polypeptide AF5 was detected by SDS-PAGE in all serotypes and antibody to this antigen was present in porcine convalescent serum. The observation that antibody binding to this polypeptide was very weak with hyperimmune gnotobiotic pig serum (C11) cannot yet be explained. Similar observations were made by Blanco et al. (1986) with hyperimmune rabbit serum against $T$. pallidum, where the polypeptide of lowest molecular mass could not be detected. The reason for these findings is uncertain although it is possible that the colonic mucosa of pigs recognized axial filament epitopes of whole, intact organisms which may have been modified during the preparation of purified axial filaments for parenteral immunization.

This investigation has identified the axial filaments of $T$. hyodysenteriae as major immunodominant antigens. Similarly, Western blot analyses of sera from patients infected with 
T. pallidum (Moskophidis \& Muller, 1984; Hanff et al., 1982; Baker-Zander et al., 1985), L. interrogans serovar hardjo (Chapman et al., 1988) and B. burgdorferi (Hansen et al., 1988) have also identified the axial filaments as immunodominant antigens.

In a recent study by Chatfield et al. (1988), pigs protected by vaccination using an intramuscular inoculation of formalin-killed $T$. hyodysenteriae showed a predominant antibody response to five $T$. hyodysenteriae polypeptides with molecular masses in the range $29-45 \mathrm{kDa}$. Although these antigens were described as outer envelope polypeptides, the SDS-PAGE profiles are similar to those presented in this investigation as axial filament polypeptides. It is possible that the outer envelope preparations described by Chatfield et al. (1988) contained axial filaments.

It has been suggested that antibodies to axial filaments may be bactericidal (Blanco et al., 1986) but the growth inhibition tests described here suggest that antibodies to axial filaments alone are not bactericidal. It is likely that hyperimmune serum was unable to agglutinate intact viable organisms as the axial filaments are located within the outer envelope and therefore inaccessible to antibody. However, antibodies to axial filament antigens may operate in conjunction with antibodies to other components of the spirochaete, e.g. the outer envelope, thus producing an effective anti-bacterial mechanism.

Further investigations of the immune response to specific antigens of $T$. hyodysenteriae should lead to a better understanding of the mechanisms of immunity and possibly to the formulation of improved vaccines.

We are grateful to Mrs P. Bland for the electron microscopy, to Mr D. Hawkins for the photography and to Miss R. Hill for technical assistance.

\section{REFERENCES}

Bailey, M. J., Cockayne, A. \& Penn, C. W. (1987). Production of murine monoclonal antibodies to the major axial filament polypeptide of Treponema pallidum. Journal of General Microbiology 133, 1805-1813.

Baker-Zander, S. A. \& Lukehart, S. A. (1984). Antigenic cross-reactivity between Treponema pallidum and other pathogenic members of the family Spirochaetaceae. Infection and Immunity 46, 116-121.

Baker-Zander, S. A., Hook, E. W., Bonin, P., Handsfield, H. H. \& LukehaRT, S. A. (1985). Antigens of Treponema pallidum recognized by IgG and $\operatorname{IgM}$ antibodies during syphilis in humans. Journal of Infectious Diseases 151, 264-272.

Barbour, A. G. \& Hayes, S. F. (1986). Biology of Borrelia species. Microbiological Reviews 50, 381-400.

Barbour, A. G., Burgdorfer, W., Grundwaldt, E. \& SteERE, A. C. (1983). Antibodies of patients with Lyme disease to components of the Ixodes dammini spirochaete. Journal of Clinical Investigation 72, 504-515.

Barbour, A. G., Hayes, S. F., Heiland, R. A., SChrumpF, M. E. \& TeSSIER, S. L. (1986). A Borreliaspecific monoclonal antibody binds to a flagellar epitope. Infection and Immunity 52, 549-554.

Baum, D. H. \& Joens, L. A. (1979). Serotypes of $\beta$ haemolytic Treponema hyodysenteriae. Infection and Immunity 25, 792-796.

Blanco, D. R., Radolf, J. R., Lovett, M. A. \& MilleR, J. N. (1986). The antigenic interrelationship between endoflagella of Treponema phagedenis biotype Reiter and Treponema pallidum Nichols strain. I. Treponemicidal activity of cross-reactive endoflagella antibodies against Treponema pallidum. Journal of Immunology 137, 2973-2979.

Blanco, D. R., Champion, C. I., Miller, J. N. \& LoveTt, M. A. (1988). Antigenic and structural characterisation of Treponema pallidum (Nichols strain) endoflagella. Infection and Immunity 56, 168-175.

Burrows, M. R. \& LeMCKe, R. M. (1981). Identification of Treponema hyodysenteriae by a rapid slide agglutination test. Veterinary Record 108, 187-189.

BurRows, M. R., Lysons, R. J., Rowlands, G. J. \& LEMCKE, R. M. (1984). An enzyme-linked immunosorbent assay for detecting serum antibody to Treponema hyodysenteriae. In Proceedings of the 8th International Pig Veterinary Society Congress, Ghent, p. 186.

Chapman, A. J., Adler, B. \& Faine, S. (1988). Antigens recognised by the human immune response to infection with Leptospira interrogans serovar hardjo. Journal of Medical Microbiology 25, 269-278.

Chatfield, S. N., Fernie, D. S., Penn, C. W. \& DougAN, G. (1988). Identification of the major antigens of Treponema hyodysenteriae and comparison with those of Treponema innocens. Infection and Immunity 56, 1070-1075.

Cockayne, A., Bailey, M. J. \& Penn, C. W. (1987). Analysis of sheath and core structures of the axial filament of Treponema pallidum. Journal of General Microbiology 133, 1397-1407.

Craft, J. E., Fischer, D. K., Shimamoto, G. T. \& SteEre, A. C. (1986). Antigens of Borrelia burgdorferi recognised during Lyme disease. Appearance of a new immunoglobulin $\mathbf{M}$ response and expansion of the late immunoglobulin $G$ response late in illness. Journal of Clinical Investigation 78, 934-939. 
Egan, I. T., Harris, D. L. \& Joens, L. A. (1983). Comparison of the microtitration agglutination test and the enzyme-linked immunoabsorbent assay for the detection of herds affected with swine dysentery. American Journal of Veterinary Research 44, 1323-1328.

Hanff, P. A., Fehniger, T. E., Miller, J. N. \& LovetT, M. A. (1982). Humoral immune response in human syphilis to polypeptides of Treponema pallidum. Journal of Immunology 129, 1287-1291.

HaNSEN, K., Hindersson, P. \& StrandberGPedersen, N. (1988). Measurement of antibodies to the Borrelia burgdorferi flagellum improves serodiagnosis in Lyme disease. Journal of Clinical Microbiology 26, 338-346.

Hardy, P. H., Fredericks, W. R. \& Nell, E. E. (1975). Isolation and antigenic characterisation of axial filaments from the Reiter treponeme. Infection and Immunity 11, 380-386.

HARRIS, D. L. \& GLOCK, R. D. (1986). Swine dysentery and spirochaetal disease. In Diseases of Swine, pp. 494-507. Edited by A. D. Leman, B. Straw, R. D. Glock, W. L. Mengling, R. H. C. Penny \& E. Scholl. Ames, Iowa: Ames University Press.

Harris, D. L., Glock, R. D., Christensen, C. R. \& KinYoN, J. M. (1972). Swine dysentery. I. Inoculation of pigs with Treponema hyodysenteriae (new species) and reproduction of the disease. Veterinary Medicine and Small Animal Clinician 67, 61-64.

Harris, D. L., AleXander, T. J. L., Whipp, S. C., Robinson, I. M., Glock, R. D. \& Matthews, P. J. (1978). Swine dysentery: studies of gnotobiotic pigs inoculated with Treponema hyodysenteriae, Bacteroides vulgatus and Fusobacterium necrophorum. Journal of the American Veterinary Medical Association 172, 468-471.

Hovind-Hougen, K. (1974). Electron microscopy of Borrelia merionesi and Borrelia recurrentis. Acta pathologica et microbiologica scandinavica B82, 799-809.

Hudson, M. J., Alexander, T. J. L. \& Lysons, R. J. (1976). Diagnosis of swine dysentery: spirochaetes which may be confused with Treponema hyodysenteriae. Veterinary Record 99, 495-500.

Joens, L. A. \& MARQuez, R. B. (1986). Molecular characterization of proteins from porcine spirochaetes. Infection and Immunity 54, 893-896.

Joens, L. A., Harris, D. L. \& Baum, D. H. (1979). Immunity to swine dysentery in recovered pigs. American Journal of Veterinary Research 40, 1352-1354.

Joens, L. A., Glock, R. D., Whipp, S. C., Robinson, I. M. \& HARRIS, D. L. (1981). Location of Treponema hyodysenteriae and synergistic anaerobic bacteria in colonic lesions of gnotobiotic pigs. Veterinary Microbiology 6, 67-77.

Joens, L. A., Deyoung, D. W., Glock, R. D., Mapother, M. E., Cramer, J. D. \& Wilcox, H. E. III (1984). The immune response of the porcine colon to swine dysentery. In Proceedings of the 8 th International Pig Veterinary Society Congress, Ghent, p, 187.
Kelson, J. S., Adler, B., Chapman, A. J. \& Faine, S. (1988). Identification of leptospiral flagellar antigens by gel electrophoresis and immunoblotting. Journal of Medical Microbiology 26, 47-53.

Kent, K. A., Lemcke, R. M. \& Lysons, R. J. (1988). Production, purification and molecular weight determination of the haemolysin of Treponema hyodysenteriae. Journal of Medical Microbiology 27, 215-224.

LAEMMLI, U. K. (1970). Cleavage of structural proteins during the assembly of the head of bacteriophage T4. Nature, London 227, 680-685.

LEMCKE, R. M. \& BEW, J. (1984). Antigenic differences among isolates of Treponema hyodysenteriae. In Proceedings of the 8th International Pig Veterinary Society Congress, Ghent, p. 183.

LEMCKe, R. M. \& BurRows, M. R. (1979). A disc growth-inhibition test for differentiating Treponema hyodysenteriae from other intestinal treponemes. Veterinary Record 104, 548-551.

Lysons, R. J., Hall, G. A., Alexander, T. J. L., Bew, J. \& Bland, A. P. (1978). Aetiological agents and pathogenesis of swine dysentery. In Proceedings of the 5th International Pig Veterinary Society Congress, Zagreb, p. M1.

LySONS, R. J., LEMCKe, R. M., BEW, J., BURROWS, M. R. \& AlEXANDER, T. J. L. (1982). An avirulent strain of Treponema hyodysenteriae isolated from a herd free of swine dysentery. In Proceedings of the 7th International Pig Veterinary Society Congress, Mexico, p. 40.

Moskophidis, M. \& Muller, F. (1984). Molecular analysis of immunoglobulins $M$ and $G$ immune response to protein antigens of Treponema pallidum in human syphilis. Infection and Immunity 43, $127-132$.

Nauman, R. A., Holt, S. C. \& Cox, C. D. (1969). Purification, ultrastructure and composition of axial filaments from Leptospira. Journal of Bacteriology 98 , 264-280.

Sand-Petersen, C. S., Strandberg-Pedersen, N. S. \& AXELSEN, N. H. (1981). A simple method for the isolation of flagella from Treponema Reiter. Acta pathologica et microbiologica scandinavica C89, 379-385.

TAYloR, D. T. \& AleXander, T. J. L. (1971). The production of dysentery in swine by feeding cultures containing a spirochaete. British Veterinary Journal 127, lviii-lxi.

Towbin, H., Staehelin, T. \& Gordon, G. (1979). Electrophoretic transfer of proteins from polyacrylamide gels to nitrocellulose sheets; procedure and some applications. Proceedings of the National Academy of Sciences of the United States of America 76, 4350-4354.

Whipp, S. C., Pohlenz, J., Harris, D. L., Robinson, I. M., Glock, R. D. \& Kunkel, R. (1982). Pathogenicity of Treponema hyodysenteriae in uncontaminated gnotobiotic pigs. In Proceedings of the International Pig Veterinary Society Congress, Mexico, p. 31. 